\title{
Nurse T. with Sheard, T. (2020) A Pandemic Nurse's Diary. Hard Ball Press.
}

\section{Review by Jeanne Bryner}

Being a critical care nurse demands creativity, cutting-edge knowledge and common sense. This country of the most acute illnesses requires physical stamina, dedication to being a team member, excellent assessment skills and adaptability to change. ICU nurses are constantly observing, listening and processing a cacophony of machines, their patients' and colleagues' body/verbal language, a plethora of medications, and physician orders and prioritizing needs before implementing treatments. They assess and evaluate after each new treatment. A never-ending wheel of needs turns. The nurse responds.

This is a non-fiction book about nursing during the COVID-19 pandemic in a New York City hospital. Nurse T with Timothy Sheard show the reader the plight of nurses who lack supplies and adequate staff but by their hearts and wit continue to show up day after day during a global pandemic. Essential workers, their life is on the line.

With two decades of experience, paper pants, shirt and face mask to protect her, Nurse T navigates the territory between her ICU COVID patients and death in New York City, 2020. She steers us through the pandemic's ambush, its surrounding misinformation, her months of duty, heartache, frustration and resolve. Her daily notations bring us so close to the bedside, we feel her breath inside the mask, the weight of her sweat dampening her scrubs. And we are relieved by her questions, the way she advocates for cutting-edge treatments and challenges authority about the lack of PPE and the outdated infrastructure of her home hospital. She is the nurse we want for our family, friends and ourselves.

Nurse $\mathrm{T}$ parts a curtain and reveals how shadowy healthcare delivery is even today, even in a country with deep pockets and brilliant minds. She bears witness to her lack of knowledge about COVID and supplies. We watch as her twelve-bed ICU unit takes on four COVID cases, then, every single bed and eventually, her entire hospital becomes a COVID hospital. She and other nurses question 'droplet only' precautions. COVID is a virus. And the Manhattan hospitals have installed fans in every ICU room to blow the virus outside. Why not here? Why not for the Medicare/Medicaid patients? This staff of caregivers? There's been no educational in-service on this new virus and her supervisor doesn't know if there will be. The pharmacy is low on first line sedation/anesthesia drugs and in the dark about when supplies will be filled.

Many of her patients are Black or Latino. They have multiple diseases, and now, COVID. The world news about the virus 'is not good.' We are beside her stepping into 'pools of bloody fluids' and placing ice bags to a fevered body. When blood clots clog the breathing tubes or lungs or invade her patients' brains, we want the new breathing tube to be patent, the lungs to clear and full neurological cognition to be restored. We sigh and share her dread when any higher up tells her 'we must have a meeting and discuss these concerns.' Our hearts do a happy dance when face shields and N95 masks arrive, purchased by a union for the staff of her hospital. 
We want her fifteen- minute lunch or break to be longer and wrapped in silence. We want the first line drugs to always be available to sedate those terrified patients on the ventilators. We want more hands on deck to turn the patients prone. We want the families to be able to visit their loved ones.

When colleagues become her patients, it seems like things cannot become worse. When she knows that fifty percent of the patients on ventilators die; she feels her care is robotic. This constant wrestling with Death and staying in a nearby motel with colleagues and not seeing her family ... It takes a toll. She has to talk a three hundred pound plus man into staying in his bed. After so long in the bed, his legs won't hold him. And she'll not be able to lift him from the floor. We want to hold our hands on either side of his full face and say, 'Listen to her, buddy. She knows her stuff.' We trust this voice who questions why Remdesivir trial treatments are denied to her hospital.

Nurse T and Timothy Sheard draw on their own critical care nursing experiences and reflections about the unending struggles of equitable healthcare delivery the world over. The voices of nurses are underrepresented in social, political and economic landscapes. This is a history we really need because it illuminates the lives of marginalized populations. Policies can be changed and infrastructure updated, if we are willing to stand up and use our bullhorn. Nurse $\mathrm{T}$ has done this with her book, and she admits to PTSD, and the value of counseling for her and her colleagues after the floodgates of COVID patients. This shared narrative is extremely valuable for all workers. We all wear masks. We go about our tasks smiling, nodding and performing, but so much boils underneath. We are not super human. There is no shame in letting go of angst with another professional or in a group or alone using a journal. Managers need to be questioned and informed of concerns; then, if there's no movement toward resolution, go higher up the ladder.

She acknowledges the multiple layers of change to be addressed. No easy answers exist, but first, issues must be brought out of the shadows to be examined. She has done this. Nobody should have to fear for their life as they prepare for a work day, but nurses did and some of them died. Terror cannot be tamped down. With a clear eye and honest voice Nurse $\mathrm{T}$ has shared her experiences with us in one book. She is a brave person who made it through the wilderness changed. Timothy Sheard spent four decades in nursing. The book's motive is not an indictment. It is not written with anger or malice. These are reasonable statements about lack of communication, desperate needs for more staff, and how crucial it is to update existing structures.

The pandemic is still very active. Never mind what billionaire is orbiting earth inside his rocket. There's work right here, right now. We trust these voices that bear witness. We are reshaped from their memorable stories and thankful for this narrative.

\section{Reviewer Bio}

Jeanne Bryner is a retired emergency room nurse, writer and teacher. Born in Appalachia, she writes about working-class lives, and teaches writing workshops in schools, universities and community venues. She has several books in print and lives near a dairy farm with her husband, David. 